\title{
Paupers and the Infirmary in Mid-Eighteenth-Century Shrewsbury
}

\author{
ALANNAH TOMKINS*
}

The earliest definitions of the poor who were deemed to deserve relief under the old Poor Law included the sick. The relative generosity of some parishes in payments for ill or injured paupers has often been noted. Yet in the mid-eighteenth century, provincial hospitals emerged as an option to complement the efforts of parish officers in some places. Mary Fissell's work on the Bristol Infirmary has established the similarity of circumstances which pushed people on to poor relief or into an infirmary, but it has not yet been determined whether there was a substantial overlap of people who used both options at the same time. ${ }^{l}$ Individuals may theoretically have been in- or outpatients in an eighteenth-century infirmary while they or their families were also receiving a parish pension or other form of poor relief, but was this ever in fact the case?

Attempts to answer such questions are problematic, owing to the scarcity of suitable charity records for the same years when relevant or useable parish records survive. Fortunately the Shropshire Infirmary, one of the first ten hospitals founded in England outside London, has left records for the mid-eighteenth century covering some of the same years for which we possess poor relief documents for Shrewsbury town parishes. ${ }^{2}$ Consequently, after a brief introduction to mid-eighteenth-century Shrewsbury, this article will examine four aspects of welfare provision in the town between 1740 and 1755 . First, the accounts of the overseers' of the poor will be used to examine the way parish relief was administered in Shrewsbury, with particular note being taken of the extent of dependency on relief in various parishes. Second, a study of "medical" relief provided to the sick poor in the town will demonstrate the variety and emphasis of treatments available from the parish. Third, name lists of patients in the Shropshire Infirmary, which survive from the hospital's opening in 1747 to 1756 , will be compared with paupers' names in Shrewsbury town overseers' accounts. This will reveal the possible extent of the overlap

*Dr Alannah Tomkins, History Department, Keele University, Keele, Staffs., ST5 5BG.

I should like to thank my doctoral supervisor, Joanna Innes, for her advice on earlier drafts of this article, Angus MacInnes for his patience in reading later drafts, and the anonymous referees for Medical History for their comments and suggestions.

\footnotetext{
${ }^{1} \mathrm{M}$ Fissell, Patients, power, and the poor in eighteenth-century Bristol, Cambridge University Press, 1991, pp. 94-5.

${ }^{2}$ Shropshire Records and Research Centre (hereafter SRRC), 2711/P/1 Shrewsbury St Julian
}

overseers' accounts 1753-65; P257/L/3/3-5

Shrewsbury St Mary overseers' accounts 1732-47, 1748-53 and 1754-64; P250/L/2/1-2 Shrewsbury

Holy Cross and St Giles overseers' accounts 1721-54 and 1755-88; 3365/723 Shrewsbury St Chad overseers' accounts 1591-1755 (accounts for 1740-55 have been lost); 3365/725 Shrewsbury St Alkmund overseers' accounts 1580-1752; 3365/727 Shrewsbury Holy Cross and St Giles overseers' accounts 1638-1754; 3909/1/1 Royal Salop Infirmary weekly board minutes 1745-1756. (The parish of Shrewsbury Holy Cross and St Giles kept two separate sets of accounts in which at times the information given differs.) 


\section{Paupers and the Infirmary in Mid-Eighteenth-Century Shrewsbury}

between town paupers and hospital patients, and show how the experiences of paupers admitted to the hospital differed from those of the average patient. Lastly, an analysis of the parish relief given to people who were definitely both paupers and Infirmary patients will illustrate the role of the Infirmary in the experiences of paupers.

\section{Shrewsbury in the Mid-Eighteenth Century}

Shrewsbury was primarily a market town providing services to inhabitants and market visitors, so it is unsurprising that around 20 per cent of its tradesmen between 1700 and 1775 dealt in food and drink. ${ }^{3}$ A distinctive feature of Shrewsbury's market in the eyes of contemporaries was the prominence of the Welsh textile trade. Cloth produced in Wales was brought to Shrewsbury for finishing and sale to clothiers; it was alleged that "on market day you would think you were in Wales". ${ }^{4}$ At some time in the eighteenth century, this trade began to wane but it did not collapse entirely until the 1790s. The town's traditional leather-working industry was also in decline by 1750 but by this time the town had developed a luxury sector to attract and amuse the gentry, and MacInnes suggests that this expanded to fill the gap left by leather and textiles. ${ }^{5}$

The River Severn is integral to Shrewsbury, and in the eighteenth century its horse-shoe curve encompassed the greater part of the town. The river's depth meant that it was navigable through and beyond Shrewsbury and the town took advantage of the relatively cheap and easy water transport it afforded to gain access to domestic and foreign produce brought via Bristol. ${ }^{6}$ Improvements in road transport allowed Shrewsbury to become a key point for through trade between north Wales, Holyhead, Liverpool and the south east of England. This development was formalized in the 1770s when Robert Lawrence established it as a staging post between London and Holyhead. ${ }^{7}$

In 1750 the population of Shrewsbury was estimated to be 8141 , spread over five town parishes. ${ }^{8}$ By 1801 this had risen to 14,739 , a count which included the 1253 inhabitants of a sixth parish located on the edge of the town; however, it is unlikely that the population of Shrewsbury increased dramatically before 1760. It experienced a spurt of growth in the later part of the century which pre-dated substantial, manufacturing expansion from 1790 onwards. ${ }^{9}$

In 1750 St Chad, with 3771 inhabitants, was the largest parish and it was also the poorest. The approach roads from Wales arrived at the town in St Chad, and Welsh migrant workers had tended to settle there when looking for work in the textile industry during the seventeenth century, for which period the parish has been described as "ghettolike". ${ }^{10}$ St Mary was the next largest parish with 1399 people and contained the castle and approach roads from the north. Holy Cross and St Giles (hereafter Holy Cross) on the east

\footnotetext{
${ }^{3}$ A MacInnes, 'The emergence of a leisure town: Shrewsbury 1660-1760', Past and Present, 1988, 120: $53-85$, p. 56.

${ }^{4} \mathrm{D}$ Defoe, $A$ tour through the whole island of Great Britain, London, Everyman, 1959, vol. 2, p. 75.

${ }^{5}$ MacInnes, op. cit., note 3 above, p. 58.

${ }^{6}$ Ibid., p. 79.

${ }^{7}$ B Trinder, 'The textile industry in Shrewsbury in the late eighteenth century', paper given at the ESRC
} 
of the town was the smallest parish with 910 people. A study of Shrewsbury in the 1690s found that these relatively large parishes could conceal considerable variations in the wealth of their populations and that poverty was particularly marked on some streets, including Frankwell in St Chad, Castle Foregate in St Mary, Coleham in St Julian, and Abbey Foregate in Holy Cross. ${ }^{11}$

The fairly detailed poor rate accounts kept in St Mary enable a closer, street-by-street analysis to be made of that parish. All the occupiers of houses were listed and where the poor rate was not levied an explanation was often given, one reason for exemption being poverty. A study of the exemptions in 1750 and 1755 revealed that Castle Hill, which ran along the base of the hill on which the castle stood, was a very poor area, while Castle Foregate and other roads in the vicinity of the castle or adjacent to the Severn (where houses were probably prone to flooding) were also relatively poor. The cluster of streets at the top of the hill around St Mary's church, including Ox Lane and Dogpole, had virtually no inhabitants who were sufficiently poor to be exempt from paying the poor rate.

\section{Poor Relief: Dependency, Pensions and the Workhouse}

An examination of poor relief in Shrewsbury must be confined to parishes and years with surviving accounts of the overseers of the poor. These exist in some form for the two parishes of St Mary and Holy Cross throughout the years 1740 to 1755 . The quality of the accounts for St Mary is occasionally poor, particularly in years when the parish paid a contractor, Henry Podmore, to assume responsibility for poor relief (as in 1753 and 1754). Lists of workhouse inhabitants are available only for 1742 and 1745 but individuals who were in the workhouse are occasionally named when purchases were made for them; people receiving regular weekly or monthly relief in St Mary were commonly named in the accounts. Overseers for Holy Cross never listed workhouse inmates systematically but again their names appear among the workhouse accounts. Recipients of regular cash doles were listed in selected years. ${ }^{12}$ Overseers' accounts for St Julian's parish survive from 1753 onwards and their quality is comparable with those from Holy Cross. The two remaining parishes of St Alkmund and St Chad have surviving accounts only for individual years in the period $1700-40$, which are of variable quality. It is unfortunate that no overseers' accounts later than the 1730 s can now be found relating to St Chad, the poorest parish in Shrewsbury, and that some of these accounts contain few details during periods when a contractor called Alker was being paid to take responsibility for all of the poor (such as in 1734).

In the period 1740 to 1755 , the cost of poor relief ranged between $£ 100$ and $£ 350$ for all the parishes in Shrewsbury where figures are known. On this point of total expenditure, it is possible to provide some comparison (albeit for single years) with the two parishes which do not possess substantial runs of surviving overseers' accounts. In 1740, St Alkmund spent $£ 16213 s 7 d$ on poor relief, while in 1734 St Chad spent a total of

\footnotetext{
$11 \mathrm{~J}$ Hindson, 'The marriage duty acts and the social topography of the early modern townShrewsbury 1695-8', Local Popul. Stud., 1983, 31: $21-8$, p. 25.
}

\footnotetext{
12 Pensioners in Holy Cross are listed for some years in SRRC, 3365/727 and for others in SRRC, $\mathrm{P} 250 / \mathrm{L} / 2 / 1$ but not all years $1740-55$ have surviving pensioner lists.
} 


\section{Paupers and the Infirmary in Mid-Eighteenth-Century Shrewsbury}

$£ 24819 s 6 d$. These figures suggest that St Alkmund's expenditure on the poor was probably slightly higher than that of Holy Cross, while St Chad's total spending was in line with some of the more expensive years endured by all three of the parishes in Table 1 twenty years later. It seems reasonable to suppose that St Chad's total bill may usually have been higher than those of the other town parishes between 1740 and 1755 but is unlikely to have been astronomic in comparison with Holy Cross, St Julian or St Mary.

\section{Table 1}

Outline of total expenditure on poor relief in three Shrewsbury parishes 1741-55

\begin{tabular}{llll} 
& Holy Cross & St Julian & St Mary \\
\hline Average spent 1741-45 & $£ 13417 s$ 10d & no info. & $£ 222 \quad 7 s \quad 4 d$ \\
Average spent 1746-50 & $£ 13616 s \quad 9 d$ & no info. & $£ 16117 s \quad 9 d$ \\
Average spent 1751-55 & $£ 15017 s \quad 4 d$ & $£ 1820 s 1 d$ & $£ 181 \quad 2 s \quad 6 d$ \\
Lowest amount spent 1741-55 & $£ 94 \quad 7 s \quad 9 d$ & $£ 1609 s 2 d$ & $£ 103 \quad 0 s \quad 4 d$ \\
Highest amount spent 1741-55 & $£ 230 \quad 0 s \quad 5 d$ & $£ 2116 s 3 d$ & $£ 35511 s \quad 1 d$ \\
\hline
\end{tabular}

An overview of poor relief distribution in Shrewsbury in the mid-eighteenth century reveals a typical range of schemes for relieving (and reducing the burden of) the poor. Workhouses were used by all five central urban parishes. ${ }^{13}$ Where records survive, parishes seem to have fluctuated between running workhouses under the direct control of the overseers and paying contractors to take responsibility for them. Contractors did not last long in this period; Henry Podmore assumed the responsibility for the poor both in and out of St Mary's workhouse in 1753 but had given up the venture by 1755; Holy Cross's contract with Samuel Jones in the early 1740s also lasted less than two years. The distribution of out relief was never decisively ended by the use of the workhouse test in either St Mary or Holy Cross. Shrewsbury parishes did not unite for poor relief purposes until 1783. ${ }^{14}$

It is difficult to determine the numbers of people who were significantly dependent on their parish in any one year, either by their receipt of a regular cash dole (or pension) or by their occupancy of a workhouse. ${ }^{15}$ Since it was rare at any time for Shrewsbury overseers to list the paupers accommodated in workhouses, the total numbers relieved throughout the year could only be guessed; however, a clearer picture emerges in St Mary during 1742 and 1745, and a reasonable estimate of the dependent poor may be attempted

\footnotetext{
${ }^{13}$ In addition to the overseers' accounts listed at note 2 above, see SRRC, Shrewsbury borough records 3365/2431 town quarter sessions book of orders 1746-70 for mention of St Chad's workhouse.

${ }^{14} \mathrm{~S}$ and B Webb, English poor law history part one:
}

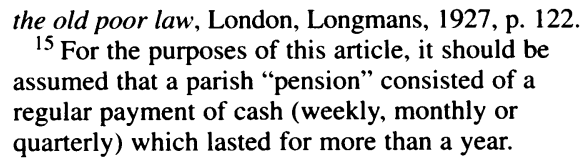
assumed that a parish "pension" consisted of a regular payment of cash (weekly, monthly or quarterly) which lasted for more than a year. 


\section{Alannah Tomkins}

in Holy Cross for 1748. A study of the extent and character of dependency will also shed light on the value of regular cash payments made by these parishes and on the manner in which workhouses were used.

In 1742, St Mary's overseers kept a monthly list of paupers in their workhouse. In the first month of the payment year, April, there were 28 people in the house. This total rapidly fell to only 15 people by July 1742 , a reduction largely accounted for by the apprenticeship of five children and the departure of seven people in the Jones and Thomas families; thereafter there were usually between 13 and 15 people in the house. At the same time, 11 pensions were paid throughout the year, in either weekly, monthly or quarterly instalments. Richard Davis, otherwise known as Dick of the Lane, received $1 s$ every week, while Margaret Lloyd, who was referred to by the parish as Mad Peg, received $4 s 6 d$ per month. Pensioners received an average of $1 s 2 d$ per week each. The lowest number of people in St Mary's workhouse plus the number of year-long pensions suggest that a minimum of 24 people were heavily dependent on parish relief at any one time in 1742 . This is not the whole story because some pensions clearly had more than one beneficiary; Anne Clempson's money also contributed to the support of her three children. This is a common problem with the study of pensions but Slack suggests that, as a rule of thumb, the number of pensions may be doubled to estimate the total number of beneficiaries; therefore, it can be estimated that there were a minimum of 35 dependent poor in St Mary in $1742 .^{16}$

A similar calculation can be made for 1745 . In this year the number of poor in the workhouse was more stable, partly because pauper children were not subject to a concerted apprenticing drive. At the start of the year, in April 1745, there appear to have been 22 people in the workhouse, of whom three died during the year, one was apprenticed, and one, Elizabeth Bevan, left. Elizabeth Downes and her four children entered the house at Christmas, whereupon her youngest child died. Elizabeth Davis was in the house for a month when she gave birth to an illegitimate child, who died at only nine days old. Therefore, 29 people were in the workhouse at some time during the year and it is likely that there were between 17 and 24 people living in the workhouse at any one time. In the same year, St Mary's parish was paying 20 pensions on a weekly, monthly or quarterly basis, yielding an average $8 d$ each, so the minimum number of dependent poor at any one time in 1745 can be estimated as 57 people. Given that the population of St Mary probably stood at around 1400, these calculations suggest that between 2.5 per cent and 3.5 per cent of its inhabitants were substantially dependent on poor relief in the early 1740 s.

Unfortunately, it is not clear why the average pension declined in value between 1742 and 1745. The constituency of poor pensioners remained the same since money continued to be given primarily to widows and women caring for children. The economic climate during 1742 was not notably harsh in comparison with 1745; however, the good harvest of 1742 did follow two years of very poor harvests and severe weather conditions. The higher pensions in 1742 may have reflected recent hardships rather than current ones. By way of comparison, an examination of pensions in 1755 and 1756 found that there were 17 and 20 pensioners in each year respectively receiving an average $1 s 4 d$ or $1 s 5 d$ per week each.

\footnotetext{
${ }^{16} \mathrm{P}$ Slack, Poverty and policy in Tudor and Stuart England, London, Longman, 1988, p. 174.
} 


\section{Paupers and the Infirmary in Mid-Eighteenth-Century Shrewsbury}

The evidence of the 1742 and 1745 lists shows that St Mary's workhouse was mainly used for families overburdened with children; of the people who experienced workhouse life at some time during 1742 and 1745, 60 per cent were children, 29 per cent were adult women, and only 11 per cent were adult men. The composition of inmates in St Mary's workhouse diverges from the "average" picture of workhouse inhabitants described by Hitchcock. ${ }^{17} \mathrm{He}$ found that 50 per cent of workhouse occupants were likely to be adult women and that only an average 34 per cent were children.

The parish of Holy Cross did not use a workhouse continuously throughout the 1740s. The house was abandoned in summer 1742 and in 1743 it was damaged by fire. As a result, parish pensions became the main source of long-term relief in the period 1742-48 and fortunately the parish kept lists of people being given regular, monthly cash doles in 1748. In April of that year, a total of 28 pensions were paid, suggesting around 56 beneficiaries or dependent poor in the parish. In a population of around 900 , this indicates a dependency rate of 6 per cent.

In June 1748, it was decided to reopen the Holy Cross workhouse, whereon the list of pensions was cut to only 10, paid from July onwards and labelled as 'Pay to the Poor that are allowed out of the workhouse'. This group included two children who had effectively been fostered by women in the parish, three women with children of their own, and a lame boy. The beneficiaries of the 18 pensions which had been cut, of whom at least 8 were widows and a further 6 were also adult women, were presumably required either to enter the house or to survive independently. This suggests that Holy Cross was effectively operating a policy of using the workhouse for the deserving adult poor and not as a place to keep children, who continued to be maintained with pensions.

Pensions were paid monthly in Holy Cross and in May 1748, before the workhouse reopened, the average payment stood at $5 s$ per month or $1 s 3 d$ per week, assuming a fourweek month. In July, the paupers who remained as pensioners received an average $4 s 7 d$ ( $1 s 2 d$ per week), suggesting that the workhouse had not dramatically reduced the cost to the parish per pensioner in the short term. The average pension remained $4 s 3 d$ per month in 1749 but had decreased a little by the early 1750s; in 1752 it stood at $3 s 6 d$ and in 1754 at $3 \mathrm{~s} 10 \mathrm{~d}$. It is possible that the workhouse test was being applied more rigorously to new claimants for relief after July 1748 than it was to existing paupers when the workhouse reopened. This may explain the gradual reduction in the average cost of pensions.

The estimated extent of dependency in St Mary and Holy Cross parishes, being 2.5-3.5 per cent and 6 per cent, was probably rather lower than that in St Chad. The absence of evidence from St Chad in mid-century makes an exact chronological comparison impossible but in 1715 (before a workhouse was in use) there were 125 pensions being paid which presumably benefited around 250 people. If the population of the parish at this time was guessed to be 3270 then dependency in 1715 stood at 7.7 per cent. ${ }^{18}$ This indicates a considerable difference between dependency in the poorest parish in the town and that in other parishes, and it can be assumed that conditions did not change

\footnotetext{
${ }^{17}$ T Hitchcock, 'The English workhouse: a study in institutional poor relief in selected counties, 1696-1750', DPhil thesis, Oxford University, 1985, p. 194.

${ }^{18}$ This is not an unreasonable assumption; in 1670 the population of the town stood at around 7100 , and
}

in 1750 at 8100 . If the proportion of inhabitants living in each of the parishes in Shrewsbury were the same in 1715 as in 1750 , one could assume that the 3771 inhabitants of St Chad's in 1750 were 500 fewer in 1715, giving a population of approximately 3270 . 


\section{Alannah Tomkins}

dramatically in St Chad because this difference was also discernible in the 1780s. When parishes in Shrewsbury united for poor relief purposes in 1783, a running total was kept of the poor from each parish who were living in the new house of industry. ${ }^{19}$ It was common for over half the inmates to come from St Chad, when a little under half of the population of the town lived in the parish.

\section{"Medical" Relief for the Sick Poor}

Aside from the regular relief given to the dependent poor, parishes commonly provided "medical" or other relief on an occasional basis for the sick poor. Such relief may have been given to people who were already dependent, or to those who did not need assistance when in good health. These medical-type payments should not be seen separately from other forms of relief, since it would be pointless to say that money given to someone who might have had a chronic condition was "medical" relief in one week but "regular" or "occasional" relief in another. Mary Fissell has observed that there is little reason to separate the payments made by overseers for medical purposes from other more miscellaneous relief money, as all poor relief spending fell more or less into the general category of health care. ${ }^{20}$ Nevertheless, by looking at the range of relief bought for paupers who were said to be sick, it is possible to gain an impression both of the cures which may have been requested by the poor, or purchased by them in more prosperous times, and also of the treatments for which the parish was willing to pay.

In addition to simple cash doles issued to the sick, Shrewsbury parishes employed both professional and lay medical people to treat the poor, and were prepared to buy a range of foodstuffs specifically to assist people during illness. St Mary and Holy Cross both paid for the services of a surgeon during the years 1740 to 1755 . St Mary had a long-standing relationship with Peter Blakeway, who was paid a fixed sum per year for his work with paupers. He presumably had a contract to treat all the parish poor for an annual fee of four guineas, although no details of the contract are evident from the surviving overseers' accounts. The parish was not always able to make prompt payment; in 1743 he was owed $£ 104$ s. Blakeway was clearly prepared to wait, since he continued to work with paupers into the 1750s. In 1752 or 1753 he was paid an additional four guineas to cure a tumour on Elizabeth Davis's shoulder. ${ }^{21}$ Blakeway was one of the three surgeons elected to the Salop Infirmary on its opening in $1747 .^{22}$ There are virtually no references to the poor being bled during illness in either St Mary or Holy Cross parish, but in the case of St Mary, Blakeway may have included bleeding as part of his contract.

Holy Cross does not appear to have had a similar contract with a surgeon and references to individual occasions when a surgeon was required are rare. An unnamed surgeon was paid £2 $10 s$ to treat Margaret Cartwright, probably in May 1747, when overseers noted that she was sick. A "mountebag" doctor, presumably of dubious status, was paid in December 1747 on behalf of the Widow Groves' daughter, Alice, to cure her eyes.

\footnotetext{
${ }^{19}$ SRRC, 83/94 Atcham and Shrewsbury Poor Law union records, daily figures in the house 1784-88.

${ }^{20}$ Fissell, op. cit., note 1 above, pp. 99-100.

${ }^{21}$ This relief might have been provided in either calendar year since the payment was not dated in the overseers' accounts which covered the period April
}

\author{
1752 to April 1753. \\ ${ }^{22} \mathrm{R}$ R James, 'Medical men in practice in \\ Shropshire, 1779-1783', Transactions of the \\ Shropshire Archaeological and Natural History \\ Society, 1920, 49: 205-20, p. 210.
}


Payments to apothecaries or for physic feature a little more regularly in both parishes. ${ }^{23}$ St Mary had another permanent arrangement with the apothecary John Wood Jr, who was working with the parish by 1740 (his bill being paid late in 1742) and who was paid $£ 4$ a year between 1750 and $1752 .{ }^{24}$ Wood, the son of a Shrewsbury gentleman, had a shop in High Pavement or Castle Street in St Mary's parish and was an early subscriber to the Salop Infirmary. ${ }^{25}$ St Mary also owed money to the apothecary Mr Thornton in 1746 but had not employed him for some time. Thornton's business was taken over by a Mr Plimley in $1747 .^{26}$ The only other apothecary named by St Mary was a Mr Prosser, possibly the Thomas Prosser who had been described as a grocer when he became a burgess in 1746; he supplied drugs to the parish in January $1755 .{ }^{27}$ Holy Cross seems to have had a less consistent approach than St Mary, making use of four different apothecaries between 1747 and 1752 . In 1747 or $1748 \mathrm{Mr}$.Winnell was paid $£ 41 s 8 d$ for unspecified goods or services. This may have been Samuel Winnell, the House Surgeon (or apothecary) at the Infirmary between 1750 and 1763. ${ }^{28}$ The apothecaries Mr Taylor and Mr Griffiths were paid once each by Holy Cross in this five years, as was Mr Plimley, the successor of Mr Thornton.

Procedures requiring specialist knowledge or equipment could be provided; in June or July 1744 , St Mary paid $£ 1$ for William Cooke to be salivated (treated with mercury) for the pox, although the overseers did not specify by whom. Lay cures were sometimes obtained. In 1751 St Mary paid Mary Harley $2 s$ for curing Anne Sockit's hand, and in 1752 Holy Cross paid Richard White's wife $10 s 6 d$ for curing a "scald head"; however, it was more usual for parishioners to be paid for miscellaneous nursing services. Nurses were not always named in overseers' accounts but where they are identified they appear to have been as poor as their patients since they occasionally needed relief themselves. Margaret Sadler, who was paid to look after Edward Tudor and to lay out one of his daughters in 1751, had been relieved during her own sickness in February 1748. After nurses, midwives were the people most frequently employed to assist paupers but their names were also often omitted from the surviving records, so it is not clear how often individual women were paid, or whether different parishes ever used the same women. St Mary called on Mrs Birch, Mrs James and Mrs Powell in this capacity; both parishes paid midwives $5 s$ for their services.

Another feature of relief given to the sick poor in Shrewsbury was the provision of drinks and foodstuffs. Alcohol and sweet foods were among the most common purchases, particularly for those about to give birth, those near to death, and those who were sick in the workhouse. Alcohol of all kinds and sugar were both used widely in the treatment of illness in the eighteenth century. The Salop Infirmary, when it opened, included a yearly entry in its accounts for wine and sugar issued from the dispensary. ${ }^{29}$ In September 1747 ,

\footnotetext{
${ }^{23}$ There is no record of the treatments supplied to paupers by apothecaries since their original bills do not survive.

${ }^{24}$ St Mary's established relationships with surgeons and apothecaries may have ended in 1753 when the parish handed over responsibility for the poor to a contractor.

25 Wood is listed in the St Mary's poor rates of 1745 paying for a shop; SRRC, 3909/6/2, annual report 1747 .
} 


\section{Alannah Tomkins}

St Mary bought bread, sugar and ale for Ann Thomas when she lay in, and two years later in October 1749 drink and sugar were bought for a woman who lay in the workhouse. Similarly, in June 1749, Holy Cross bought two quarts of ale, a pound of sugar and a nutmeg for Mrs Harris who was in labour. Widow Jeffris was bought half a pint of wine just before her death in Holy Cross in August 1753, as was Edmund Robinson's wife before her death in St Mary in January 1753. Adults were given brandy, sack and gin, while children got biscuits, apples and tarts. ${ }^{30}$ Among the workhouse accounts for both parishes there are numerous purchases of white bread and sugar specifically for sick (if unnamed) inmates, and there are many more occasions when sickness is not mentioned as the reason for such purchases but may be inferred. Workhouse inmates also received, periodically, spectacles, wigs and ointment.

\section{The Infirmary and Parish Poor Relief}

The Salop Infirmary was opened in April 1747, with 40 beds for inmates and a dispensary for the treatment of outpatients. ${ }^{31}$ It was designed to assist the labouring poor of Shropshire who were incapable of paying for their own medicines. ${ }^{32}$ How many of these poor needed and received parish poor relief at the same time?

The author of the pamphlet proposing the foundation of the Shropshire Infirmary had a low opinion of the quality of parish provision in cases of illness, echoing the stereotypically critical characterization of parish relief and parish officers by pamphleteers in the mid-eighteenth century: "the little money that is in such cases to be expected from parish officers is seldom sufficient to provide them with a proper diet, much less to pay for their medicines, attendance etc". ${ }^{33}$ This judgement initially seems rather unfair, given the evidence of the overseers' accounts from the parishes of St Mary and Holy Cross, since both medicines and special dietary provisions were made available for the sick, and paupers in St Mary were used to being treated by the same surgeon as Infirmary patients. Unfortunately, financial records like overseers' accounts are not able to show the frequency with which cures were needed and sought by, but denied to, the parish poor.

Undoubtedly, the opening of an infirmary in Shrewsbury increased the options open to poor labouring people, assisting some who would probably have suffered in silence and siphoning off others who would have gone to their parish officers and asserted a claim to

\footnotetext{
${ }^{30}$ For example, see among others St Mary's overseers' accounts, note 2 above, 18 February 1744 , 31 March 1744, 11 June 1748, 22 March 1755, 3 April 1755.

${ }^{31}$ For an administrative history of the hospital, see W B Howie, 'The administration of an eighteenthcentury provincial hospital: the Royal Salop Infirmary', Med. Hist., 1961, 5: 134-55. This article says little about the patients in the Infirmary beyond procedures for admittance and reasons for discharge. This is presumably because the surviving records of the hospital list the names of patients, and their dates of admission and discharge between 1747 and 1756, but give no other details about their geographical origins or ages. Patients admitted following an
}

accident are noted, but this is the only diagnostic information given.

${ }^{32}$ The statutes of the Salop Infirmary, Shrewsbury, 1752. Rule 48 specified that people who were able to subsist and pay for their own medicines were not to be admitted. Rule 58 stated that in the case of two patients being equally well qualified to take a place in the hospital the priority should be given to the person who lived furthest away. It is not clear, however, how many patients did attend who were some distance from home.

${ }^{33}$ A proposal for erecting an infirmary for the poor-sick and lame of this county and neighbourhood, Shrewsbury, 1737, p. 1. 


\section{Paupers and the Infirmary in Mid-Eighteenth-Century Shrewsbury}

relief. What was the extent to which both were required and obtained simultaneously, and what was the place of the Infirmary in the careers of the urban poor?

As people with local knowledge about poor individuals, overseers would have been well placed to facilitate links between subscribers, who could nominate people to places on the Infirmary's books, and prospective patients. Overseers were relatively unlikely to be subscribers personally, but they could have known whether parish clergy, town magistrates or prominent ratepayers were subscribers. Parish vestries or overseers might also have initiated a parish subscription, which would have entitled parish officers themselves to nominate poor patients in their official capacity. Parish subscriptions (or the active promotion of requests by paupers to be nominated) would have been in the interests of the ratepayers, assuming that paupers receiving residential care or at least medical assistance from an infirmary would lighten the burden to be borne by the poor rate. Some hospital supporters thought a parish subscription so advantageous that they could not understand why they were not universally taken up by parishes. ${ }^{34}$

Shropshire parishes were not among the early subscribers; this was partly a result of Salop Infirmary's failure to solicit parish subscriptions. In 1757, ten years after it had opened, there were still only seven corporate subscribers, four of which were trade societies. In this year, Condover, a large parish to the immediate south of Shrewsbury, made the sole parochial subscription. St Mary's parish, while not subscribing, had earned the right to nominate two inpatients and unlimited numbers of outpatients following a decision in 1754 to exempt the Infirmary from all parochial taxes because of its location within the parish. ${ }^{35}$ Other parishes remained largely impervious to the advantages of an Infirmary subscription in 1770 when there were still only four subscribing (one being St Chad, which had subscribed from 1769). Yet in 1773 the Infirmary trustees woke up to the fact that parishes represented an untapped source of income and the annual report of that year urged the Shropshire clergy to promote parochial subscription. By 1780, the number of parish subscribers had risen somewhat, to twelve.

As in other counties, hospital policy had been instrumental in determining the extent of parishes' involvement as subscribers. In some places parochial subscriptions were explicitly barred, or hospital rules forbade the admission of paupers. The Winchester Infirmary did not consider paupers to be among the objects of the charity, and the Exeter hospital, which opened in 1741, would not accept parish subscriptions until $1795 .^{36}$ The Norfolk and Norwich hospital excluded paupers on the grounds that those on relief already had access to medical treatment, while the Radcliffe Infirmary in Oxford refused admittance to workhouse inmates for fear of the spread of infection. ${ }^{37}$ The Northamptonshire Infirmary may have been fairly unusual in that it actively sought parochial subscriptions from the time it opened and, what is more, maintained its close contact with parishes; it opened in 1744 and 48 parishes subscribed in the decade

\footnotetext{
${ }^{34}$ A Berry, 'Patronage, funding and the hospital patient c. 1750-1815: three English regional case studies', DPhil thesis, Oxford University, 1995. p. 100.

${ }^{35}$ SRRC, P257/B/3/4, Shrewsbury St Mary churchwardens' accounts, 21 April 1754.

${ }^{36} \mathrm{~J}$ Woodward, To do the sick no harm, London,
}

\author{
Routledge, 1974, p. 150, for Winchester; Berry, op. \\ cit., note 34 above, p. 96, for Exeter. \\ ${ }^{37} \mathrm{~S}$ Cherry, 'The role of a provincial hospital: the \\ Norfolk and Norwich hospital, 1771-1880', Popul. \\ Stud., 1972, 26: 291-306, p. 295; E G Thomas, 'The \\ old poor law and medicine', Med. Hist., 1980, 24: \\ $1-19$, p. 5 , for the Radcliffe Infirmary.
}


1765-74. ${ }^{38}$ Worcester Infirmary initially had 14 parochial subscribers but the hospital's relationship with parishes was chequered. After 1752 it rejected parish subscriptions and, although a few Warwickshire parishes found their way on to the list of subscribers by the 1760s, the governors considered rejecting them again in 1792 because they tended to fall into unacceptable arrears with their subscription payments. ${ }^{39}$ According to Howie, the Salop Infirmary's relationship with parishes was problematic in the 1780s when it became apparent that they were not always willing to remove a pauper from the Infirmary once he or she had been cured. In 1788 the hospital introduced an admission deposit of a guinea for patients nominated by parish officers. ${ }^{40}$

Even when parishes did subscribe or acquire rights to nominate patients to hospitals, it is not always clear that they regularly exercised the latter. It seems that parish officers were sometimes instrumental only in mediating between sponsors and patients, or in transporting suitable infirmary patients to the doors of the charity without having nominated them. In the Infirmary trustees' minutes of 14 July 1750, the board heard the complaint of Thomas Beale Esquire, who had been charged $15 \mathrm{~s} 10 \mathrm{~d}$ for the burial of a patient he had recommended. There had apparently been a breakdown in communications between the sponsor and the deputizing parish officer, as the patient "was buried in the manner directed by the parish officer who brought her and that he was acquainted what the price would be" (italics mine). Of all the references to Infirmary patients in Shrewsbury overseers' accounts in the period 1747 to 1755 , nearly half are in terms of carrying or taking people to the Infirmary. Nevertheless, paupers certainly could find their own way into the hospital. At a meeting of 24 October 1747, the Infirmary trustees agreed that the chairman should write to the churchwardens of St Chad's parish to complain about the failure of the workhouse master to keep the patient Richard Davis's head clean. It is unfortunate that the records of the Shropshire Infirmary do not contain the names of the individual patients' sponsors at this date, so it is not clear how Davis secured a nomination for hospital treatment. ${ }^{41}$

Some information about the access of paupers to Infirmary places can be obtained by a close study of Shrewsbury's surviving overseers' accounts for the same years that patient name-lists were kept in the Infirmary trustees' minutes. A comparison of the names of inand outpatients being treated by the Infirmary with the names of paupers in town parishes who were referred to as ill in overseers' accounts can reveal the extent to which town paupers made use of the Infirmary charity at the same time that they received parish poor relief. Admittedly, the label "ill" is vague and it is not certain that overseers were scrupulous in noting every one of their paupers who was sick during the year; however, this seemed the best way to make such an exercise manageable and productive. ${ }^{42}$

\footnotetext{
38 Woodward, op. cit., note 36 above, p. 17; Berry, op. cit., note 34 above, pp. 99-100.

${ }^{39} \mathrm{~J}$ Lane, Worcester Infirmary in the eighteenth century, Worcestershire Historical Society, 1992, pp. 20-1.

${ }^{40}$ Howie, op. cit., note 31 above, p. 51.

${ }^{41}$ SRRC, 3909/1/24 Royal Salop Infirmary rough minute book 1778-1784, for the earliest surviving references to the names of sponsors.

${ }^{42}$ It was necessary to limit in some way the number of pauper names to be compared with
}

patients for two reasons. First, collecting names of paupers from overseers' accounts proved very time consuming, and often unsatisfactory in that some individuals are only ever referred to by their surnames, an alias, or by some means other than their first name and surname. This meant that any comparison of paupers with patients gave rise to a large number of people for whom it was impossible to either confirm or rule out a link. Second, the frequent recurrence of individuals with the same first names and surnames in the town meant that a 


\section{Paupers and the Infirmary in Mid-Eighteenth-Century Shrewsbury}

The poor quality of the overseers' accounts in some years effectively prevents their use in such a comparison; those for St Mary in 1753 are useless, being merely summary accounts of totals paid to Henry Podmore, who had contracted to run the parish workhouse. Consequently, links were made between the names of paupers and Infirmary patients for five of the ten possible years. Comparisons also had to take into consideration parish overseers' accounting years. Overseers' accounts do not cover a calendar year but run from 25 March to 24 March, or for around fifty-two weeks covering these dates approximately. Therefore, in order to ensure the fullest possible coverage of overlapping names in the comparison for patients in 1755, for instance, the overseers' accounts for $1754 / 5$ and $1755 / 6$ were scanned for the names of sick paupers. ${ }^{43}$

Two categories of overlap between patients and parish poor emerged. First, if people were mentioned by overseers as being in the Infirmary or having been carried to it, and their names matched with patients, they could definitely be identified as pauper patients. Second, where patients and paupers shared the same first names and surnames without confirmation that they were the same person, they were identified as possible pauper patients.

Holy Cross sent the largest number of paupers who definitely gained admission to the hospital. It is possible that either paupers themselves or parish officers developed a relationship with parish residents who subscribed to the hospital and used the connection to secure nominations. Nominations did not come from the vicar of Holy Cross who did not subscribe in the years 1747 to 1756 . The largest number of possibles from any parish came from among paupers in St Mary, which may reflect the fact that the parish itself had some rights of nomination.

In the five years studied, paupers from these parishes may have accounted for an average 4 per cent of admissions; however, this represents the maximum figure possible by this method of calculation. If individuals in the "possible" category are scrutinized more

Table 2

Pauper patients in Salop Infirmary in selected years from 1747 to 1755

\begin{tabular}{lcccc} 
St Mary & Holy Cross & St Julian & Total & $\begin{array}{c}\% \text { of } \\
\text { admissions }\end{array}$ \\
\hline $0: 4$ & $0: 3$ & no info. & 7 & 3.5 \\
$0: 9$ & $0: 4$ & no info. & 13 & 5.5 \\
$0: 11$ & $5: 4$ & no info. & 20 & 4.1 \\
$0: 7$ & $3: 4$ & no info. & 14 & 2.2 \\
$2: 19$ & $0: 1$ & $2: 12$ & 36 & 4.7 \\
$2: 50$ & $8: 16$ & $2: 12$ & 90 & 4.0 \\
\hline
\end{tabular}

comparison of all pauper names with patients gave rise to a list of names where two or more paupers with identical names could have been linked with two or more patients with similarly identical names. Such links are inconclusive.

\footnotetext{
${ }^{43}$ Births and deaths were also included, which, although not "illness", possibly preceded or followed medical assistance.
} 


\section{Alannah Tomkins}

closely, it becomes obvious that some were more likely to have been Infirmary patients than others. Some individuals have unusual surnames, or are noted by both the parish and the hospital as dying at about the same time, and so are probably genuine pauper patients; for example, it is almost certain that the patient Reynold Edwards, who died in September 1755, was the Reginald Edwards buried by St Julian in the same month. By contrast, there were three patients in 1755 called Richard Davis, any one of whom could have been the pauper from St Mary with the same name; however, it is equally possible that none of them was, as there were numerous men with exactly the same first name and surname living in Shrewsbury at the time. Therefore it is likely that the total extent of overlap between paupers and patients is somewhat lower than these figures project.

It is also likely that there was a fairly small amount of overlap between patients in the Infirmary and paupers from the town as a whole. The three parishes of Holy Cross, St Mary and St Julian contained 41 per cent of the town's population at this time, so if the average 4 per cent of admissions deriving from pauper patients in these parishes was assumed to be broadly correct, the percentage of Infirmary places taken by paupers from Shrewsbury would be around 9.8 per cent. Having said this, it is likely that these three parishes were home to less than 41 per cent of all patients from Shrewsbury. St Chad was notably the poorest parish in the town and may have been home to proportionately more patients than other parishes. The figures available from the Shrewsbury house of industry in the 1780s suggest that 50-55 per cent of the poor in the house came from St Chad and only 37-38 per cent came from the three parishes in Table $2 .{ }^{44}$ If these percentages also applied to Infirmary patients in the $1750 \mathrm{~s}$, then it is likely that around 10.8 per cent of Infirmary places were taken by Shrewsbury paupers.

Admittedly, some patients may have been paupers from elsewhere in the county. Rule 58 gave precedence to those seeking admission to the hospital who lived furthest away, but there is no evidence relating to the geographical origins of patients in the Infirmary at this time. In the Bristol Infirmary (which was also a county hospital) 84 per cent of patients came from the town or its close environs, and Risse also writes, if in more general terms, about many patients at Edinburgh coming either from the city or the surrounding villages. ${ }^{45}$ It seems logical that the pulling power of the hospital should have been strongest in the near vicinity and have become much weaker over long distances. If this were true, then paupers from Shrewsbury would have been among the parish poor most likely to have secured an admission, but this speculation cannot be confirmed.

The overlap between Shrewsbury paupers and Infirmary patients was limited and may have been minimal. There are a number of probable reasons for this. Clearly, individuals among the labouring poor were most likely to be picked up by either the parish or by a charity, depending on their gender and the stage they had reached in the life-cycle. It has been shown that the typical patient in infirmaries across the country was an adult, usually male, between twenty-five and fifty-nine years old. There is no age data for patients in Shrewsbury but there was certainly a greater number of men admitted than women in these years; in 1755, for example, 409 men were admitted in contrast to 350 women. Poor relief in St Mary and Holy Cross in Shrewsbury was primarily directed at women, who may have been elderly and who were often described as widows, and at children. For the most part,

\footnotetext{
${ }^{44}$ SRRC, 83/94 Atcham and Shrewsbury Poor Law union records, daily figures in the house 1784-88.
}

\footnotetext{
45 Guenter B Risse, Hospital life in enlightenment Scotland, Cambridge University Press, 1986, p. 85.
} 


\section{Paupers and the Infirmary in Mid-Eighteenth-Century Shrewsbury}

adult males were not significantly dependent since they did not usually receive a pension or a place in the workhouse. The concentration of Poor Law resources on the elderly and children may have provided the rationale for the new voluntarily funded charity to attend to other sections of the population. This does not preclude the possibility that individual poor people benefited from both forms of relief at different points in their lives.

This pattern may also have been a function of the Infirmary's emphasis on the short-term nature of its relief. The pamphlet which originally proposed the foundation of a hospital in Shrewsbury suggested that, ideally, the Infirmary should treat "occasional objects of charity, such as are disabled from work", and later an annual report referred to patients as "the laborious poor, the most useful part of society"; the hospital wanted to treat short-term complaints with a view to setting the labouring poor back to work. ${ }^{46}$ Given these priorities, paupers would have seemed awkward patients to treat. Much parish money was spent to maintain people in habitual dependency (through a pension or a place in a workhouse), and as paupers were frequently aged, children or otherwise unemployable, they would have been restored to health only in order to return to dependency.

Alternatively, this small amount of overlap may represent pauper choice as much as hospital policy. Paupers may have tended to go to a relief agency they knew rather than one they did not, meaning that a short-term crisis occasioned by illness in the life of a dependent pauper was much more likely to be met by a short-term increase in parish spending on that individual rather than by a resort to other agencies. Conversely, people not habitually or previously dependent on parish money may have been more willing to turn themselves over to the care of a charity than to a parish because such an action may have been seen as less degrading and more appropriate to their circumstances.

The role played by parish paupers as patients in this new infirmary charity suggests that the experience of some form of dependent poverty was more pervasive and varied in mideighteenth-century urban society than has been assumed so far. If parishes, hospitals and other relief agencies catered for substantially different subsets of the population who could conceivably have been described as poor, this implies a more far-reaching but also more fragmented coverage of the collective needs of "the poor". These agencies formulated different criteria for entitlement and either engendered or responded to different patterns of reliance by their users. Infirmaries offered a more specific and limited form of relief than parishes, and carefully selected those who were to benefit from it, while simultaneously pouring scorn on the poor quality and high cost of Poor Law provisions. By contrast, parishes waited for needs to arise and be drawn to their attention; paupers were effectively self-selecting (except where their requests for relief were denied by vestries or parish officers).

\section{The Place of the Infirmary in the Experiences of the Poor}

A close examination of the overseers' accounts for three Shrewsbury parishes and the Infirmary patient lists from 1747 to 1756 produces sixteen people who were definitely in the Infirmary and receiving poor relief. It is instructive to compare this set of people with the profile of all Infirmary patients to see how they differed.

\footnotetext{
${ }^{46}$ A proposal, op. cit., note 33 above, p. 1; SRRC, $3909 / 6 / 2$ annual report 1755 .
} 


\section{Alannah Tomkins}

One striking point about Table 3 is the much higher proportion of pauper patients who experienced life as inpatients. Around half of all patients were taken into hospital residence, whereas more than four-fifths of paupers spent some time occupying a hospital bed. Perhaps the most telling difference between the average patient and the pauper patient was the vastly increased likelihood that the latter would die. The death rate among all patients was only 5.4 per cent in 1755 and never rose above 10 per cent in the period 1747-56 yet pauper patients had a 50 per cent chance of dying. What is more, one of the men discharged "cured" died less than two months later.

As paupers in Shrewsbury habitually received help from their parish during illness, it is probable that few paupers would have been admitted to the Infirmary with minor illnesses, since parishes would have assisted and effectively cured some paupers without the hospital becoming involved. If only problematic or serious conditions or those requiring surgery were eventually referred to the hospital, this would explain the higher death rate among pauper patients and may also account for pauper patients' greater propensity to become inpatients. It is difficult to comment on the connection between age and death, as no information about age is given for any of the Salop patients and only a little can be inferred about the paupers. Only two of the pauper patients, Lydia Butcher and Hugh Hughes, are described in the overseers' accounts as "old", and other more marginal indicators (such as the child-bearing capacity of pauper patients or patients' wives) tend to suggest that pauper patients were often middle-aged.

Although women feature more prominently than men among all paupers in Shrewsbury, male paupers are more numerous among these hospital patients (taking nine of the sixteen places). Therefore, the gender split mirrors that among all patients, meaning that male paupers were much more likely than female paupers to receive a successful nomination for admission. This may be connected with the character of the poverty experienced by men on parish relief. Men were less likely than women to be permanently dependent, and so were more likely to need only occasional parish relief. The hospital was clearly assisting paupers who fitted the hospital's brief, people who if restored to health might have been returned to work. Significantly, the two people carried to the Infirmary by their parishes in the period 1747 to 1755 who do not then appear among the patients (and who were presumably rejected) were both women. ${ }^{47}$ Nevertheless, this policy did not prevent the admission of pauper men who later died. Half of the eight deaths among pauper patients occurred among the men.

The differences between the experiences of the average patient and pauper patients may be clarified by a closer look at the parish relief which pauper patients received in the period before and then during their time in the hospital, from 1740 to 1755.

Edward Cartwright is a good example of someone who required parish help only occasionally. All the payments he received in 1749, the year he went into the Infirmary, were made in the month when he became a patient, and his need for relief was a result of his illness; he was bought sugar and given small doles of money. The other distinct time when Cartwright needed help was during February and March 1754, the last months of his

\footnotetext{
${ }^{47}$ St Mary paid Jane Tudor $6 d$ "infirmary" on 19
} July 1755 and Holy Cross paid for Widow Murphy to be taken to the Infirmary on 6 April 1753. Neither woman appears listed as a patient. 
Paupers and the Infirmary in Mid-Eighteenth-Century Shrewsbury

Table 3

The experience of patients in the Salop Infirmary compared with that of pauper patients

All Patients (1755)

Paupers (1747-56)

\begin{tabular}{|c|c|c|c|c|}
\hline & No. & $\%$ & No. & $\%$ \\
\hline \multicolumn{5}{|l|}{ Admissions } \\
\hline Inpatients, unknown sex & 4 & $0.5 \%$ & 1 & \\
\hline Outpatients, unknown sex & 2 & $0.3 \%$ & 0 & \\
\hline Women inpatients & 116 & $15.2 \%$ & 2 & \\
\hline Women outpatients & 189 & $24.7 \%$ & 1 & \\
\hline Women, in- and outpatients & 45 & $5.8 \%$ & 3 & \\
\hline Men inpatients & 155 & $20.3 \%$ & 4 & \\
\hline Men outpatients & 218 & $28.5 \%$ & 2 & \\
\hline Men, in- and outpatients & 36 & $4.7 \%$ & 3 & \\
\hline Total & 765 & $100.0 \%$ & 16 & \\
\hline Total men & 409 & $53.5 \%$ & 9 & $37.50 \%$ \\
\hline Total women & 350 & $45.8 \%$ & 6 & $56.25 \%$ \\
\hline \multicolumn{5}{|l|}{ Discharges } \\
\hline Cured & 436 & $70.8 \%$ & 6 & \\
\hline $\begin{array}{l}\text { Much better/better/little better/ } \\
\text { relieved/supposed cured }\end{array}$ & 37 & $6.0 \%$ & 1 & \\
\hline Incurable & 6 & $1.0 \%$ & 1 & \\
\hline Dead & 33 & $5.4 \%$ & 8 & $50.0 \%$ \\
\hline Other & 104 & $16.8 \%$ & 0 & \\
\hline Total & 616 & $100.0 \%$ & 16 & \\
\hline
\end{tabular}




\section{Alannah Tomkins}

wife's first pregnancy in the parish. Cartwright was clearly independent except during periods of unusual expense.

At least four other pauper patients appear to have received parish relief only while they were patients or as a result of their illnesses. In St Julian's parish, Mary Yeomans became sick in the September and October of 1754 when the parish paid her $7 s 6 d$ in seven separate payments. In mid-October the parish paid for two men to carry her to the Infirmary, where she was admitted as an inpatient and the parish paid for shifts, a handkerchief and an apron while she remained in hospital. A bill paid for her to $\mathrm{Mr}$ Symonds (Samuel or Joshua Symonds, an apothecary) in late October was presumably for treatments purchased before Mary's admittance to the hospital. 48 "Savage" Jones was also bought clothes by St Julian's parish while an inpatient, and had one other bill paid (to the same woman who made the clothes) but received no additional relief. Lydia Butcher, called The Old Butcher by her home parish of St Mary, seems to have been given only $2 s$ relief while she was an outpatient, and Hugh Hughes (also called "Old") was given $6 s 6 d$ in six payments between September and November 1754 when he was admitted as an inpatient. A fifth patient, who may fall into this group, Thomas Morris, is more of a puzzle because it is impossible to be certain when he was admitted to hospital; there were numerous patients with the same first name and surname admitted in the 1750s and the pauper Thomas Morris from St Mary was first paid when ill in February 1752. Nevertheless, he and his wife received only $13 s 6 d$ in total between 1752 and Thomas's burial from the Infirmary in 1754.

Mary Caton's family received the majority of the poor relief allocated to them by Holy Cross as a consequence of illness or death but some members also had experience of life in the workhouse. Mary Caton's two sons John and Joseph were both buried by the parish, in 1742 and 1744 respectively, both aged four. John was technically illegitimate, being baptised on the same day his parents married, and so the $£ 2$ paid to "John" Jones for Caton's bastard in March 1741 probably represents money effectively paid to the contractor of the workhouse, Samuel Jones, for additional expenses incurred in looking after John Caton when he was sickly. Another $6 d$ was paid for Mary's sick child in the workhouse in January 1742. Tragically for John, his mother may not have been in Shrewsbury when he died in May, as in April she was paid 10s to go to Salisbury. She did not appear again in the overseers' accounts until November 1743. After her second son Joseph's burial in October 1744, Mary Caton was not given out relief again until she was carried to the Infirmary in January 1749 and her burial was paid for in February.

A further three pauper patients who appear to have needed relief only during sickness were workhouse inmates themselves before or during their time as patients. John Howle only appears in the Holy Cross overseers' accounts during one month, August 1751, when he was ill in the workhouse. He was bought ale and wine before being carried to the Infirmary. He was accepted as an outpatient but died later the same month. Holy Cross bought ale for Elizabeth Lloyd in the workhouse in October 1753, which suggests she was ill; the parish paid to take her to the Infirmary in the following January and also paid to bury her in March 1754. In 1751 St Mary's parish bought Mary Clarke, their workhouse inmate, a yard of flannel because she was an outpatient. She also received a shift, shoes

${ }^{48}$ James, op. cit., note 22 above, p. 213. 
and an apron in the same spring and summer but did not appear in the accounts as receiving relief again until September and October 1754.

John Harris and his family are named much more frequently in Holy Cross overseers' accounts than the other pauper patients listed above, but they were still essentially people who were independent of the parish at most times until John's final illness. The family experienced some difficulty (unspecified by the parish) in October and November 1748 when they received numerous cash doles and the parish paid for a midwife and other costs associated with birth when John and Margaret's son Sam was born in June 1749. John became an outpatient in September 1749 and was made an inpatient in October. The parish bought him a shirt while he was in the hospital and he was returned to being an outpatient in November. At some time after he became an outpatient for the second time he was taken into the workhouse and given extensive "medical" relief in the form of special foods before his death in May 1750. He was bought sack and other drink, mutton, eggs, sugar and white bread on several occasions, and finally custards were bought for him four times in the month immediately before his death.

Similarly, Edward Tudor required only occasional relief throughout the 1740s and early 1750s but in 1755 he was cared for in St Mary's workhouse between spells in the Infirmary. On 30 August 1755, Tudor was both discharged as an inpatient apparently "cured" and was paid $6 d$ in St Mary's workhouse. "Being ill", he was readmitted as an inpatient just seven days later on 6 September 1755. Tudor rented his own house under normal circumstances. He was listed in the poor rate assessment of 1754 living in Castle Hill and the parish paid for a lock for his door in August 1755, the same month when he apparently spent time in the workhouse. This means that the workhouse was being used specifically as a place of residential care during his sickness. Edward Tudor or his wife also received numerous cash doles during the overseers' payment year 1755 (spring 1755 to spring 1756) but the payments were not sufficiently regular to be considered as a parish pension.

The remaining four pauper patients experienced some long-term dependency on parish relief. Gilbert Davis needed only occasional relief in the early 1740 s but in July and August 1746 he became ill or was injured and the parish bought him a crutch. At some time after this he was awarded a parish pension, since he appears among the 28 pensioners listed in 1748. He did not remain a pensioner after the workhouse was reopened, so presumably he found means to support himself until early the following year. In February 1749 the parish paid $2 s$ towards his lodging and in June paid to redeem his clothes from pawn and gave him $4 s$ to go to London. He had returned by September and in October was given another pension of $6 d$ per week. Davis was admitted to the Infirmary as an inpatient in November 1750 and was discharged cured in December; however, the cure was not permanent since Holy Cross parish proceeded to pay for his lodging (somewhere other than the workhouse) and washing, and for a pint of sack before his death in February 1751.

Richard Hughes also came from a family which was periodically dependent on the parish. A Richard Hughes was relieved by Holy Cross from April 1743 onwards, whether this was the father or his lame son, who was also called Richard and who eventually became the Infirmary patient, it is difficult to tell. Richard Hughes's lame son was among the parish pensioners listed in 1748 who were allowed to carry on as pensioners after the workhouse opened; however, the pension ended in June 1749. In the following year the 


\section{Alannah Tomkins}

parish paid to carry Richard to the Infirmary, where he was admitted as an inpatient on 1 September 1750. After three weeks he became an outpatient and he was discharged cured in October. One of the men called Richard Hughes was later relieved in the workhouse. In 1751 and 1752 he was given money or goods on the understanding that he leave the workhouse, and in 1753 he was bought ale in the workhouse possibly because he was ill.

Thomas and Mary Partridge were a brother and sister who both appear to have lived in the workhouse in the early 1750 s and both became Infirmary patients. An inventory of the Holy Cross workhouse taken around 1750 refers to John Partridge's box. John was Thomas and Mary's father, which suggests that the whole family entered the workhouse at some time and brought household goods in with them. Payments are made for both children among the workhouse accounts in 1751 and 1752. Thomas Partridge was admitted to the Infirmary as an inpatient twice, in July 1748 and October 1749. On both occasions he was discharged "incurable" after about a month, so his workhouse residency probably came after his time as a patient, but presumably while he continued to suffer from his complaint. His sister was admitted as an inpatient in January 1752 and she remained in the hospital for over a year until April 1753; at this point she was made an outpatient. She remained on the hospital's books until her death in February 1754. This means that Mary appeared among the workhouse poor before she became an inpatient; it is not known where she lived between being made an outpatient and her death.

Around half of these pauper patients spent some time as workhouse residents in the years 1740-55. This is unusual, given the infrequency with which the names of workhouse inmates occur among the workhouse accounts, and suggests that a combination of illness and workhouse residency could indicate serious bad health. This was probably not the fault of the workhouse conditions but rather the result of parish policy, to use the workhouse specifically for the care of the sick. The experience of the workhouse by pauper patients, particularly by those who were dying, such as John Howle and John Harris, shows that it was being used to provide residential care which included a specialized diet. This appears to have been true for both St Mary and Holy Cross, although some of the most detailed evidence for these pauper patients relates to Holy Cross. In Harris's case, the workhouse was operating like a hospice.

Few of the paupers had been dependent on their parishes for a long time when they became patients. Only Richard Hughes (father or son) can be decisively linked to a family which received a pauper pension. This implies that the workhouse was being used to relieve a particular category of pauper, the occasionally dependent; people who were able to maintain independence at most times but who required significant relief when suffering serious illness. It also means that the Infirmary was admitting paupers who were not among the long-term dependent. This may have been the practical result of hospital policy, or because the sick poor in the workhouse received Infirmary sponsorship more frequently than other paupers when parishes subscribed or when they were able to influence the nomination of patients by individual subscribers.

It is possible to make three tentative claims as a result of this research. First, paupers seem potentially to have had access to some of the same treatments and medical personnel that were available to Infirmary patients because parishes paid for them. Second, paupers from Shrewsbury apparently did not comprise the majority or even a significant minority of patients in the Shropshire Infirmary during its first years of existence. Despite 
criticisms of parishes by the founders of the hospital, it certainly did not remove much of the responsibility for the medical relief of the sick poor from the parish. The Infirmary treated paupers who had only occasional need of parish assistance or who had not been dependent on their parish for long. This suggests that the reach of different strains of poverty, and the conception of entitlement to relief or charity among those who disbursed these forms of welfare, may have been more complex than has been appreciated to date. Third, people who were receiving some poor relief at the same time as their encounter with the Shrewsbury hospital charity had a markedly different experience to that of most patients and suffered a much higher death rate. This disparity was probably the consequence of Shrewsbury parishes having already treated paupers' minor illnesses and using the workhouse to provide residential care. A place in the Infirmary was sought (by parishes or paupers) in cases of serious illness and was a last resort rather than a first port of call. Research on other hospitals which admitted paupers, such as Northampton, may reveal whether this pattern is representative of a pauper's lot in hospital towns, or whether local variations gave rise to a series of ways in which provincial hospitals made an impact on the circumstances of the parish poor. 